\title{
Screening of Di-2-Ethyl Hexyl Phthalate (DEHP) Degrading Bacteria and its Characterization by Liquid Chromatography Mass Spectrometry Analysis
}

\author{
Madhavi Rashmi ${ }^{1 *}$, Sonal Suman ${ }^{1}$ and Tanuja ${ }^{2}$ \\ ${ }^{1}$ Department of Botany \& Biotechnology, T.P.S College, \\ Patliputra University, Patna-800020, Bihar, India \\ ${ }^{2}$ Department of Botany, Patliputra University, Patna-800020, Bihar, India \\ *Corresponding author
}

\section{A B S T R A C T}

\begin{tabular}{l} 
K e y w o r d s \\
$\begin{array}{l}\text { Plasticizer, DEHP; } \\
\text { Biodegradation; } \\
\text { phylogenetic } \\
\text { studies, } \\
\text { environmental } \\
\text { parameters, LCMS } \\
\text { analysis }\end{array}$ \\
\hline Article Info \\
\hline $\begin{array}{l}\text { Accepted: } \\
\text { 10 April } 2020 \\
\text { Available Online: } \\
\text { 10 May } 2020\end{array}$ \\
\hline
\end{tabular}

DEHP (di-ethyl hexyl phthalate) is widely used as a plasticizer and it adversely affects humans. In this study, one of the promising DEHP-degrading strain T28 had been selected among isolated pure bacterial strain from rubbish landfill soil near the hospital area, Patna. The bacterial strain T28 was capable of consuming DEHP as a sole source of carbon and energy. By analysing morphological, biophysical, biochemical characteristics, gram staining technique followed by the analysis of 16s rRNA phylogenetic studies, the strain was identified as Bacillus subtilis (Genbank Accession no. CPO230367). The mechanism of biodegradation and its characterization at different environmental parameters influencing the degradation process in contaminated soil have also been examined. The results of this study showed the optimal $\mathrm{pH}$ value ranges (7.0-8.0) optimal temperature ranges $\left(37-50^{\circ} \mathrm{C}\right)$ while salinity could tolerate up to $5 \%$ which influenced the degradation rate in soil. We also investigated the effect of different carbon sources, nitrogen sources and different DEHP concentrations on its degradation. The isolated strain Bacillus subtilis degraded more than $99 \%$ of $250 \mathrm{mg} / \mathrm{l}$ of DEHP within $24-48 \mathrm{hrs}$. The metabolites or end products were detected by liquid chromatography and mass spectrometry (LCMS) analysis. We hope that these findings can provide some information in the bioremediation of DEHP from contaminated soil.

\section{Introduction}

Phthalates are a group of compounds employed in the fabrication of plastics and diverse other industrial applications (Lin Y. et al., 2018). Phthalates are released into various ecosystems: land, water and air because of their expanded application (Zhang L. et al., 2015 and Zhang Y. et al., 2015). If there is an increase in phthalate level then the ladies would had been related with endometriosis and gestational duration with precocious breast development (Toft G. et al., 2012). DEHP could cause central nervous system inhibition and renal injury in mice due to its significant lethal or mutagenic effects (Gao et 
$a l ., 2017)$. DEHP is one amongst the foremost commonly used plasticizers and is typically applied in such plastic products as polyvinylchloride (PVC), toys, and medical devices. DEHP is taken into account as one of the most resistant phthalate esters because of its long hydrocarbon chain (Chang et al., 2004).

It has been reported that the humans are affected by DEHP due to its exposure in our daily lives which may result in dysfunctioning of endocrine, reproductive and nervous systems (Lo et al., 2014; Net et al., 2015 and Chen et al., 2016). Biological methods have been given more attention due to their environmental friendly nature, low cost, and contaminant mineralization. DEHP is liable to the microbial degradation and studies had shown this phthalate could be degraded by microorganisms because the sole carbon and energy sources (Chen et al., 2007; Meng et al., 2015 and Pradeep et al., 2015).

This study aims that a bacterium which incorporates a remarkable degradation capability towards DEHP was isolated from the rubbish landfill soil near a hospital. Batch experiments were performed at different temperatures, $\mathrm{pHs}$, salt concentration, different DEHP, different carbon sources and nitrogen sources to further optimize the DEHP biodegradation and its molecular characterization by liquid-chromatography mass-spectrometry analysis.

\section{Materials and Methods}

\section{Chemicals}

DEHP (99\% purity) was acquired from Accu Standard Inc. The stock solution of DEHP (10 $\mathrm{mg} / \mathrm{ml}$ ) was prepared in corn oil and kept at $4^{\circ} \mathrm{C}$ until use. Higher purity grade chemicals were used throughout the experiment. The minimal salt medium (MSM) consisted of the following chemicals (mg/l): (NH4)2SO4, 1,000; KH2PO4, 800; K2HPO4, 200; MgSO4.7H2O, 500; FeSO4, 10; $\mathrm{CaCl} 2,50$ and the $\mathrm{pH}$ was maintained to $7.0 \pm 0.1$ with $\mathrm{HCl}$ or $\mathrm{NaOH}$, unless otherwise specified (Fang et al., 2010). DEHP was added solely as the carbon source. All the glassware and media were autoclaved at $121^{\circ} \mathrm{C}$ and $101 \mathrm{kPa}$ for $20 \mathrm{~min}$ before use.

\section{Isolation of plasticizer degrading bacterial strain and culture conditions}

Microbes using DEHP as a sole source of carbon was isolated through an MSM-culture procedure. The initial culture was established by adding $1 \mathrm{~g}$ of fresh soil taken from rubbish landfill contaminated with plastics near the hospital area of Patna, Bihar (India) with 100 $\mathrm{ml}$ minimal salt media (MSM) in the flask (Zhao et al., 2016).

The flask was kept static for $30 \mathrm{~min}$ after shaking at $125 \mathrm{rpm}$ for $30 \mathrm{~min} .1 .0 \mathrm{ml}$ of supernatant was inoculated into a new flask containing $100 \mathrm{ml}$ of sterilized MSM supplemented with DEHP from the flask to enrich the culture. The flasks were shaken at $125 \mathrm{rpm}$ and $35{ }^{\circ} \mathrm{C}$ for $48 \mathrm{~h}$ (Li et al., 2012). Then $150 \mu \mathrm{l}$ of medium with OD 6001.0 was moved from the flask and inoculated by the spread plate method into a nutrient agar medium. After incubation at $37^{\circ} \mathrm{C}$, few wellseparated individual colonies of different morphological types appeared and purify it with further repeated streaking on agar plates. Among the isolates, strain T28 was able to significantly degrade DEHP.

\section{Identification of isolated strain}

The strain T28 was identified on the basis of its morphology, physicochemical characteristics, and analysis of the 16S rRNA gene sequencing. The $16 \mathrm{~S}$ ribosomal RNA gene from the bacterial isolate was amplified 
by specific universal primers: $8 \mathrm{~F}$ (5'AGAGTTTGATCCTGGCTCAG3') and 1541R (5'AAGGAGGTGATCCAGCCG CA3') (Edger et al., 2004). The sequencing of amplification products was done by Yaazh Xenomics (Coimbatore, India) and the similarity of the nucleotide sequence was determined by the BLAST search in NCBI from NT database. The multiple sequence alignments were performed by program MUSCLE 3.7.

The resulting aligned sequences were cured by employing the program $G$ block $0.91 \mathrm{~b}$.This $\mathrm{G}$ blocks eliminates poorly aligned positions and alignment noise was removed by divergent regions (Talavera and Castresana 2007).The phylogeny analysis and Program PhyML 3.0 was performed. The program Tree Dyn 198.3 was employed for the rendering of tree (Dreeper et al., 2007).

\section{Effect of different physiological conditions}

The degradation of DEHP $(20 \mathrm{mg} / \mathrm{l})$ by $\mathrm{T} 28$ under different $\mathrm{pH} \quad(5.5,7.0,8.5$ and 10.5), temperature $\left(24,37\right.$ and $\left.50^{\circ} \mathrm{C}\right)$ and salinity $(5 \%, 10 \%$ and $15 \%)$ conditions was examined to determine the optimal conditions for biodegradation. After $48 \mathrm{~h}$ of incubation, taken OD at $600 \mathrm{~nm}$ of the samples. Experiments were performed in triplicate (Ting Yang et al., 2018).

\section{Effect of different chemical conditions}

The degradation of DEHP by T28 at different glucose sources (sucrose, lactose, mannose and dextrose) and different nitrogen sources (peptone, beef extract, yeast extract and casein) was done to determine optimal conditions for degradation.

\section{Substrate utilization test}

To examine the ability of T28 to utilize DEHP, T28 was cultured in MSM broth which was supplemented with $200 \mathrm{mg} / \mathrm{l}$ DEHP as a sole source of carbon and energy. The cell growth was measured by taking optical density at $600 \mathrm{~nm}$ by using a UVspectrophotometer.

\section{Analytical method}

The intermediate metabolites were analyzed by liquid chromatography-mass spectrometry (LC-MS) with the electrospray ionization (ESI) source, employing a full scan for the mass range of $50 \mathrm{e} 400$.

ESI mass spectral data were obtained in positive mode and the probe temperature was $300^{\circ} \mathrm{C}$. The optical density of the culture was measured at $600 \mathrm{~nm}$ (OD600) using a UV spectrophotometer.

\section{Results and Discussion}

Identification and characterization of the bacterial strain $\mathrm{T} 28$

After the screening process, the most potent bacterial isolate named T28 was selected. The strain was gram-negative, rod-shaped and flagellated with non-spore forming. After cultured for $18-24 \mathrm{~h}$ at $37^{\circ} \mathrm{C}$, this strain T28 formed red, opaque and irregular elevated colonies with smooth margin on nutrient agar.

The strain T28 identified as Bacillus cereus through its morphological characteristics, biochemical characteristics and 16s rRNA gene sequencing. According to the NCBI BLAST analysis of its 16S rRNA gene sequence, strain T28 belonged to the genus Bacillus of cereus family (GenBank accession no. CPO230367).

Fig. 1 illustrates the phylogenetic relationship of T28 with its close relatives. This isolate belongs to the same genus as the one isolated by Quan CS et al., (2005). 


\section{Effect of different physiological conditions}

\section{Effects of $\mathrm{pH}$ and temperature on biomass and DEHP biodegradation}

The effect of $\mathrm{pH}$ and temperature on DEHP degradation by Bacillus subtilis is shown in Figure-2 \& Figure-3 respectively. Hydrogen ion concentration in the culture medium greatly influence bacterial growth as $\mathrm{pH}$ limited enzyme activities, degradation of PAEs was particularly sensitive to low $\mathrm{pH}$ (Fan et al., 2004). The accumulation of intermediates of degradation such as phthalic acid makes the culture medium acidic and inhibits further bacterial degradation of the intermediates (Xu et al., 2005a). In the present investigation, the OD 600 increased rapidly when the culture $\mathrm{pH}$ was increased from 5.5 to 7.0. When the $\mathrm{pH}$ increased from 7.0 to 8.5 DEHP degradation rate decreased. The DEHP degradation rate and the OD 600 increased rapidly with the increase of temperature from $37^{\circ} \mathrm{C}$ to $50^{\circ} \mathrm{C}$. However, at $28^{\circ} \mathrm{c}$ temperature, the microbial biomass did not very much, the DEHP degradation rate decreased notably. Based on the above results, the optimal $\mathrm{pH}$ and the temperature selected for DEHP degradation Bacillus sp. T28 for subsequent experiments was selected as 7.0 and $50^{\circ} \mathrm{C}$ respectively.

\section{Effect of salinity or $\mathrm{NaCl}$ concentration on DEHP degradation}

Salinity is an important factor affecting microbial growth and pollutant degradation, but there are just a few halo tolerant strains in degrading PAEs that have been published in previous reports. Burkholderiacepacia DA2 was isolated by Wang et al., (2003) from marine sediments for degradation of DMP, which could tolerate a salt concentration from $0 \%$ to $1 \%$. In the present investigation, the bacterial strain T28 could degrade DEHP with the salinity ranging from $0 \%$ to $5 \%$ as illustrated in Figure 4 (Wang et al., 2003). Its high degradation efficiency made T28, a potent degrader.

\section{Effect of chemical factors on DEHP degradation}

The highest rate of degradation was seen on dextrose among the selected glucose sources (sucrose, mannose, lactose, and dextrose) and on yeast extract, it showed the highest degradation among chosen nitrogen sources (peptone, beef extract, yeast extract and casein) as shown in Figure 5. and Figure 6.

\section{Identification of metabolite by LCMS analysis}

The mass spectral analysis of the compound showed the parent ion peak at $\mathrm{m} / \mathrm{z} 321.25$ as shown in Figure 7. The fragment peaks patterns showed at $\mathrm{m} / \mathrm{z}$ ion peaks at $\mathrm{m} / \mathrm{z}$ 301.15 base peaks Figure 7. presents the metabolic intermediated identified in DEHP degradation by Bacillus subtilis. The metabolites of DEHP degradation by Bacillus cereus were extracted at different time intervals and identified by LC-MS (liquid chromatography- mass spectrometry) method. The metabolites were identified by comparing the mass spectrum at a particular retention time (RT) with published mass spectra from the database. The molecular mass of the degraded compound is 301.15 at retention time $9.01 \mathrm{~min}$. as depicted in Figure 8. and the degraded end product was4,5B is [(trimethylsilylethynyl)] benzene-1,2diamine. Molecular Formula $\mathrm{C}_{16} \mathrm{H}_{24} \mathrm{~N}_{2} \mathrm{Si}_{2}$

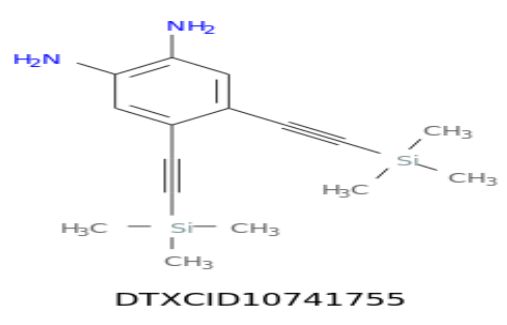




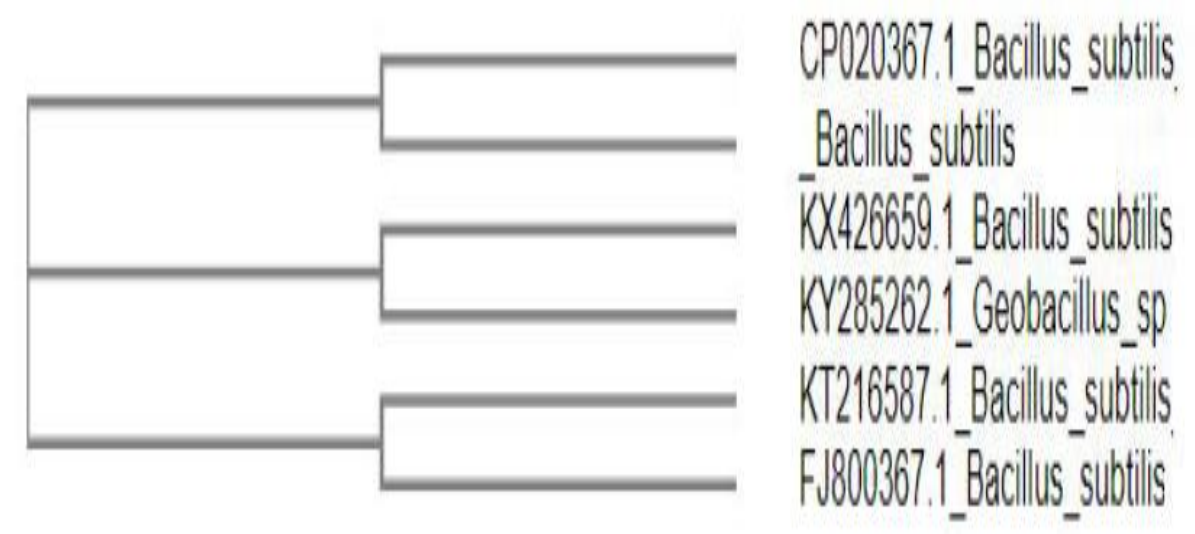

Figure.1 Phylogenetic tree of Bacillus_subtilis; The sequence bar equals 0.02 changes per nucleotide position

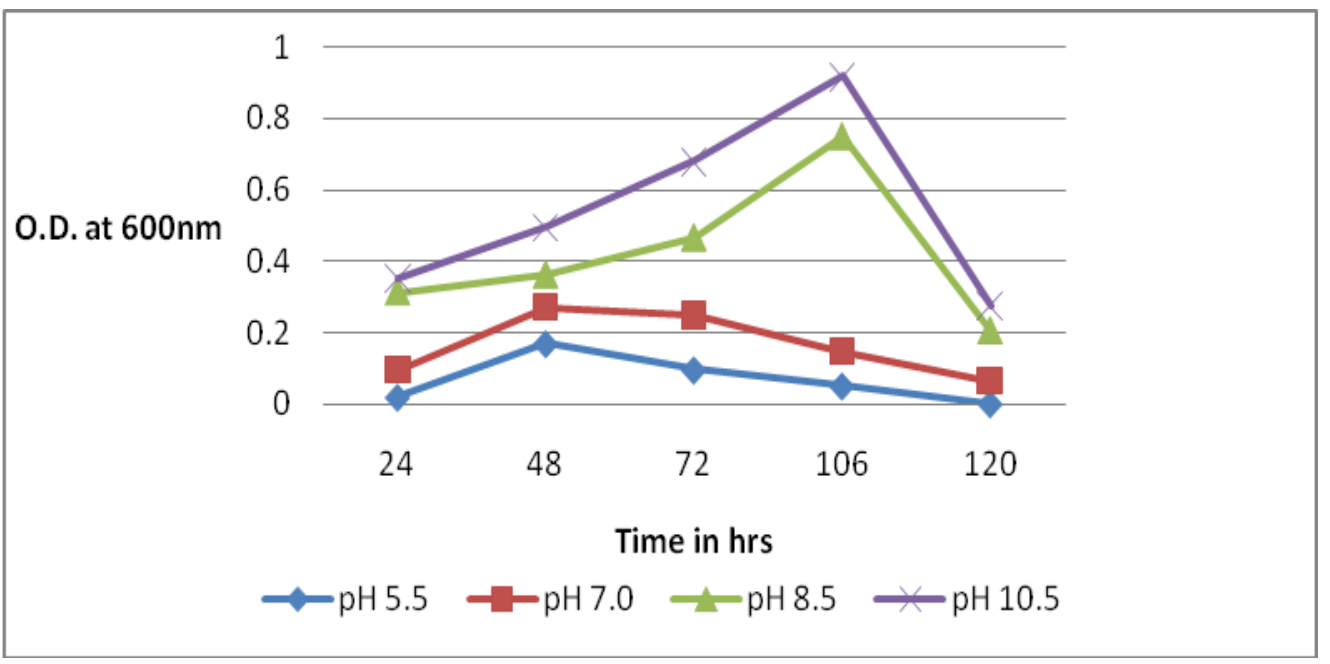

Figure.2 Degradation of DEHP at different $\mathrm{pH}$

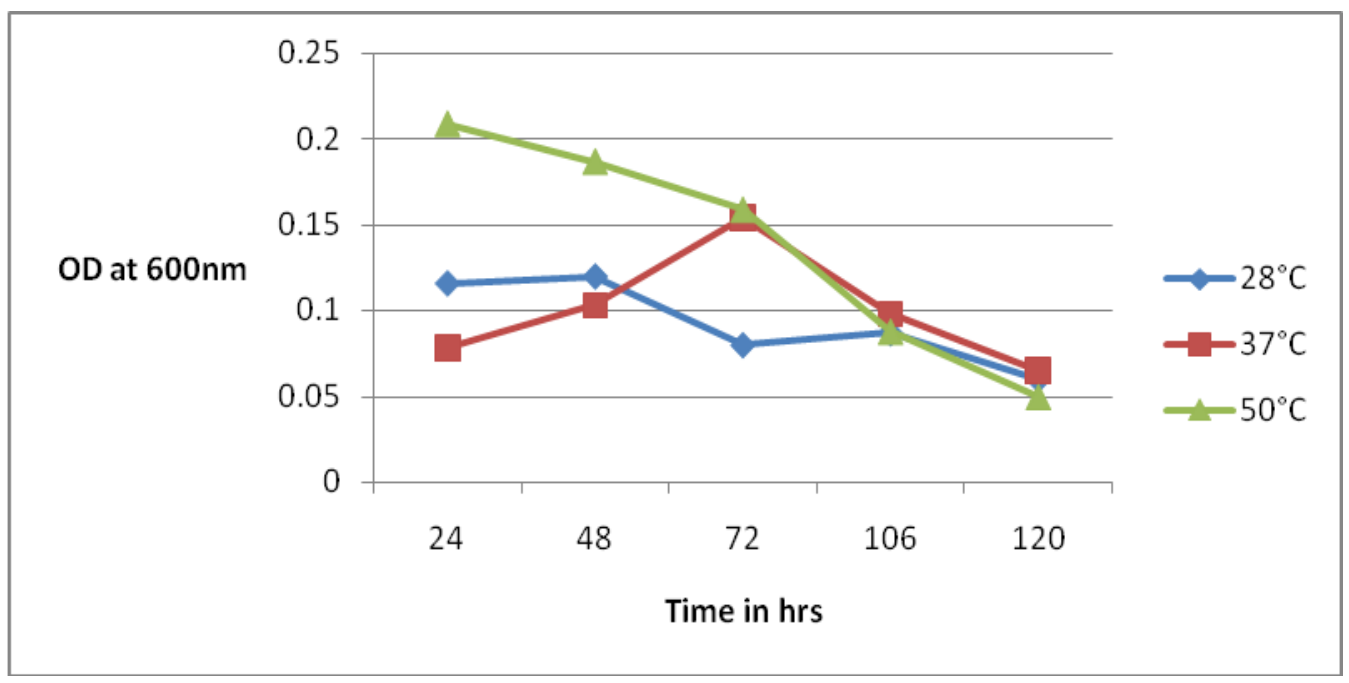

Figure.3 Degradation of DEHP at different temperature 


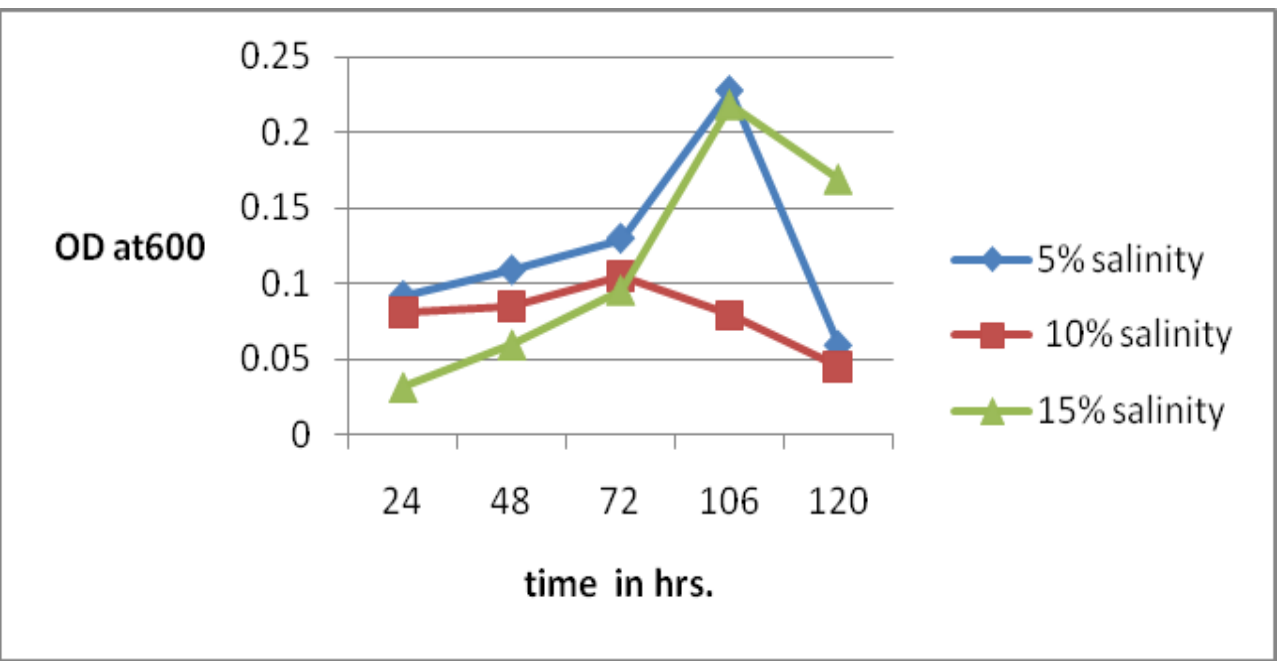

Figure.4 Degradation of DEHP at different salt concentrations

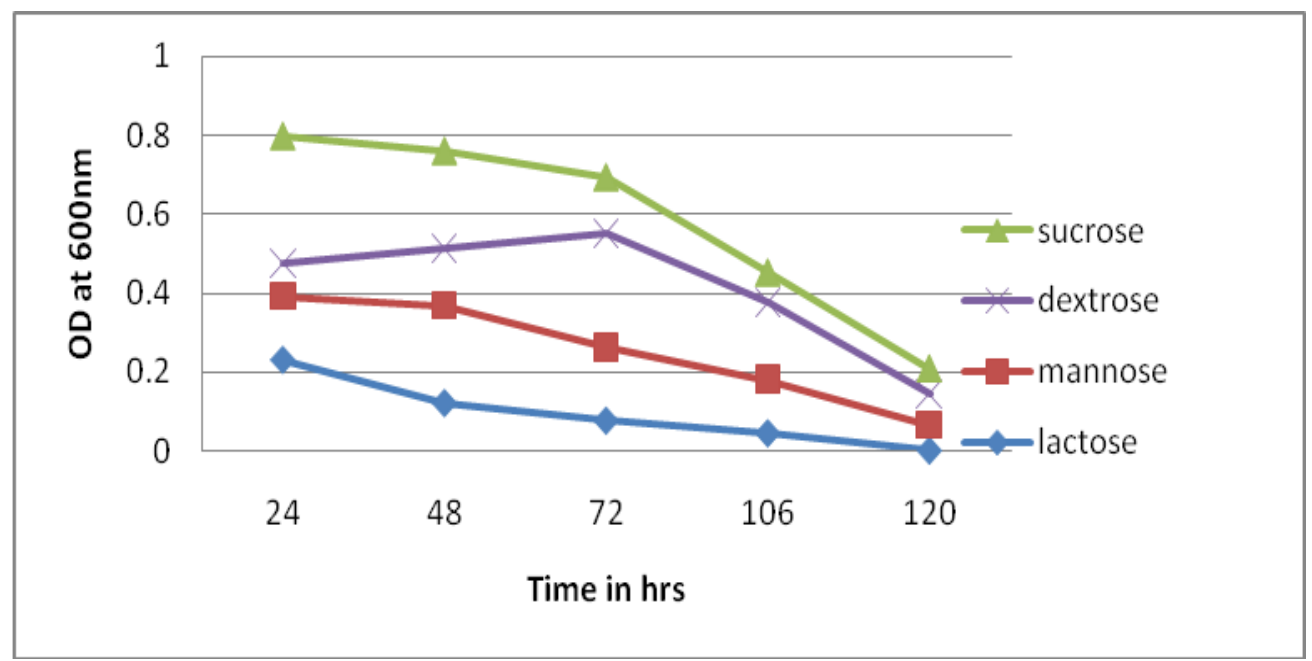

Figure.5 Degradation of DEHP at different glucose sources

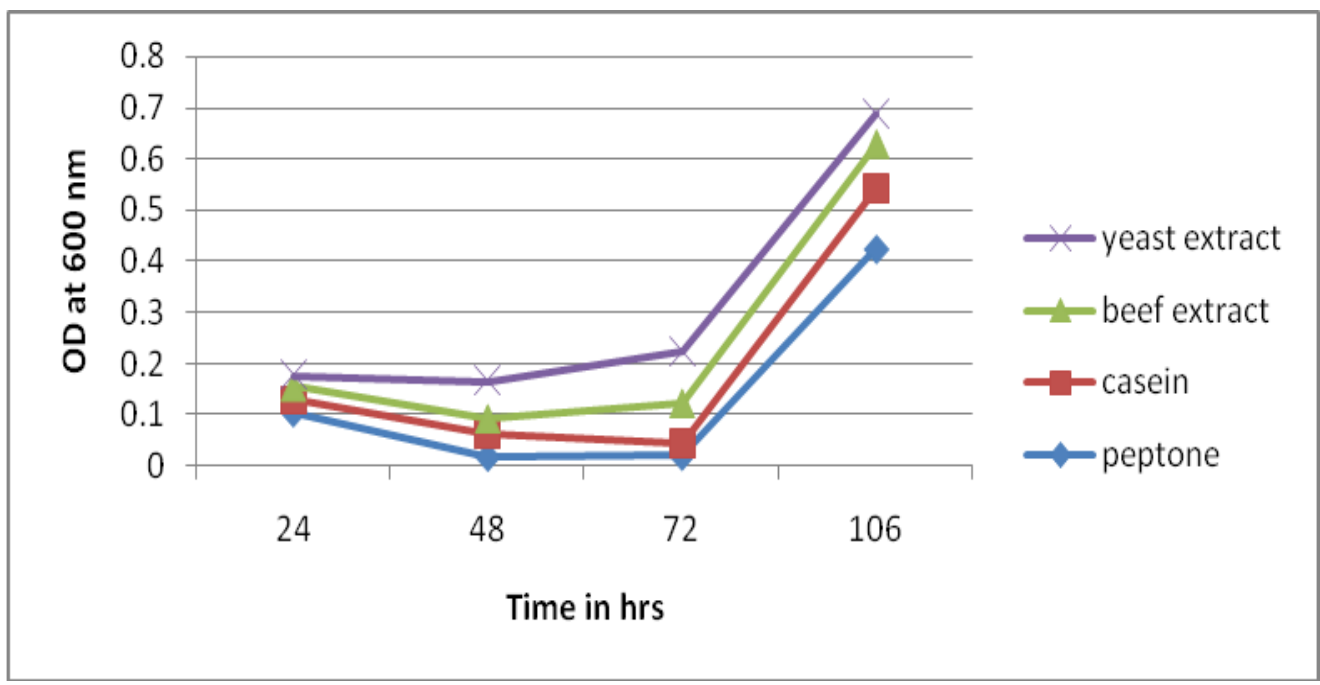

Figure.6 Degradation of DEHP at different nitrogen sources 


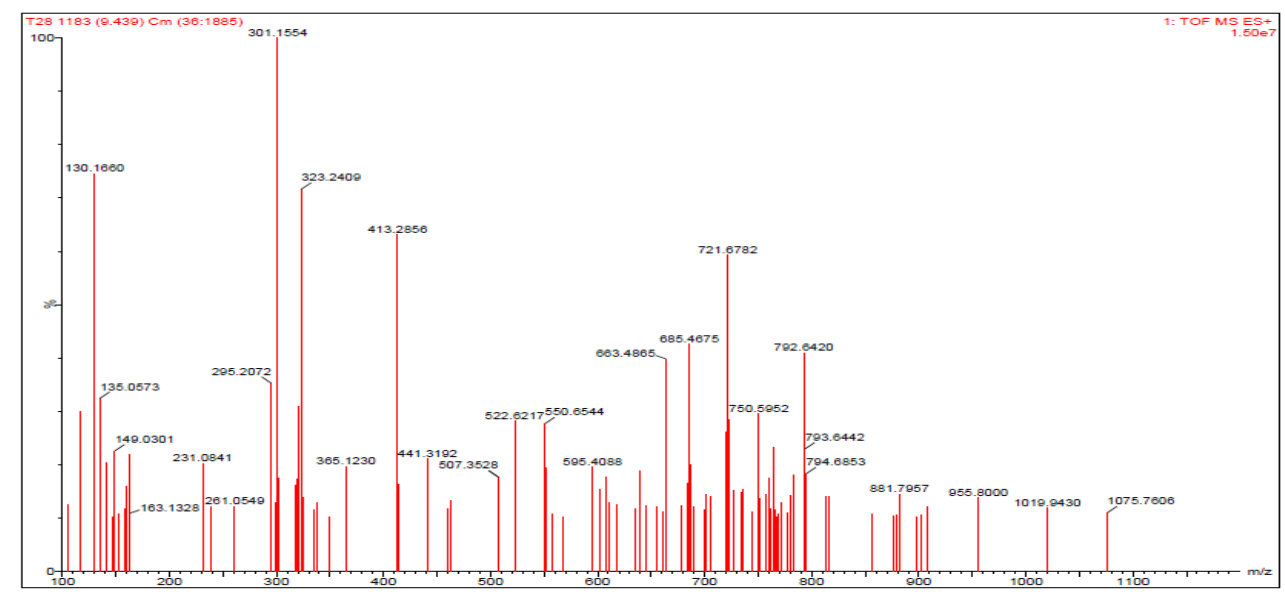

Figure.7 The mass spectrum of DEHP degraded intermediate compounds, X-Axis contains mass in relative to charge ratio $(\mathrm{m} / \mathrm{z})$ while $\mathrm{y}$-axis contains a relative abundance

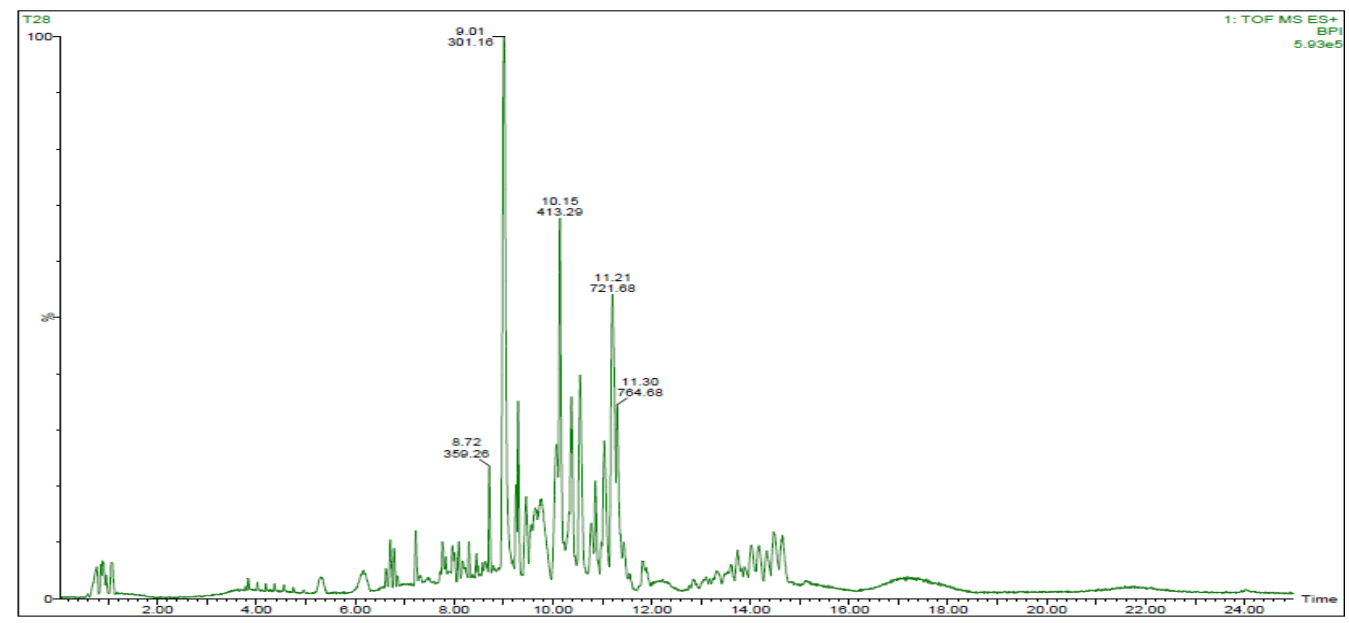

Figure.8 DEHP degradation metabolic intermediates identified by LC-MS

The results obtained in the present study showed that DEHP could be rapidly degraded by Bacillus_ subtilis isolated from rubbish landfill soil. The optimum $\mathrm{pH}$ for the degradation was 7.0. and optimum temperature was $37^{\circ} \mathrm{C}$ and the end product obtained after the LC-MS analysis was 4,5Bis [(trimethylsilylethynyl $)]$ benzene-1,2diamine.

\section{Acknowledgement}

The authors gratefully acknowledge Principal, T.P.S. College, Patliputra University Patna, for providing infrastructural facilities. This research did not receive any specific grant from funding agencies.

\section{References}

Chang, B., V., Yang, C., M., Cheng, C., H., and Yuan, S, Y., 2004. Biodegradation of phthalate esters by two bacteria strains, Chemosphere. 55: 533e538.

Chen, H., Zhang, W., Rui, B., B., Yang, S., M, Xu, W., P., and Wei, W. (2016). Di (2-ethylhexyl) phthalate exacerbates non-alcoholic fatty liver in rats and its potential mechanisms, Environ. Toxicol. Pharmacol 42: 38-44. 
Chen, J., A., Li, X., Li, J., Cao, J., Qiu, Z., Qing, Z., and Shu, W. 2007. Degradation of environmental endocrine disruptor di-2-ethylhexyl phthalate by a newly discovered bacterium, Microbacterium sp. strain CQ0110Y, Appl. Microbiol. 74(3): 676-82.

Dereeper, A., Guignon, V., Blanc, G., Audic, S., Buffet, S., Chevenet, F., Dufayard, J., F., Guindon, S., Lefort, V., Lescot, M., Claverie, J., M., and Gascuel, O. 2008. Phylogeny. fr:robustphylo genetic analysis for the non-specialist. Nucleic Acids Res. 1:36.

Edgar RC 2004 MUSCLE: multiple sequence alignment with high accuracy and high throughput. Nucleic Acids Res 32(5):1792-1797.

Fan, Y., Wang, Y., Qian, P., Y., and Gu, J., D. 2004. Optimization of phthalic acid batch biodegradation and the use of modified Richards model for modelling degradation. Int. Biodeterior. and Biodegr.53:57e63

Fang, C., R., Yao, J., Zheng, Y., G., Jiang, C., J., Hu, L., F., Wu, Y., Y., and Shen, D., S. 2010. Dibutylphthalate degradation by Enterobacter sp. T5 isolated from municipal solid waste in landfill bioreactor, Int. Biodeter. Biodeg. 64: 442e446.

Gao, H., T., Xu, R., Cao, W., X., Qian, L., L., Wang, M., Lu, L., Xu, Q., and Yu, S., Q. 2017. Effects of six priority controlled phthalate esters with longterm low dose integrated exposure on male reproductive toxicity in rats, Food Chem. Toxicol. 101: 94-104.

Li, C., Chian, X., L., Chen, Z., X., Deng, Z., Y., and $\mathrm{Xu}, \mathrm{H} ., 2$ 2012. Biodegradation of an endocrine-disrupting chemical di n-butyl phthalate by Serratia marcescens C9 isolated from activated sludge. Afr. J. Microbiol. Res. 6 (11): 2686-2693, 702e710.
Lin, Y., Wang, L., Li, R., Hu, S., Wang, Y., Xue, Y., Y., H., Jiao, Y., Xue, Y., Y., H., Jiao, Y., Wang, Y., and Zhang, Y. 2018. How do root exudates of bok choy promote dibutyl phthalate adsorption on mollisol? Ecotoxicol. Environ. Saf. 161:129-136.

Lo, D., Wang, Y., T., and Wu, M., C., 2014. Hepato protective effect of silymar in on di (2-ethylhexyl) phthalate (DEHP) induced injury in liver FL83B cells, Environ. Toxicol. Pharmacol. 38:112e11

Meng, X., Niu, G., Yang, W., and Cao, X. 2015. Di (2-ethylhexyl) phthalate biodegradation and denitrification by Pseudoxanthomonas sp. Strain, Bioresour. Technol, 180: 356e359..

Net, S., Semp, R., Delmon, t., A., Paluselli, A., and Ouddane, B. 2015. Occurrence, fate, behaviour and ecotoxicological state of phthalates in different environmental matrices, Environ. Sci. Technol. 49: 4019e4035

Pradeep, S., Josh, M., S., Binod, P., Devi, R., S., Balachandran, S., Anderson, R., C., Benjamin, S., 2015. Achromobacter denitrificans strain SP1 efficiently remediates di (2-ethylhexyl) phthalate, Ecotoxicol. Environ. Saf. 112: $114 \mathrm{e} 121$.

Quan, C., S., Liu, Q., Tian, W., J., Kikuchi, J., and Fan, S., D. 2005.Biodegradation of an endocrinedisrupting chemical ethylhexyl phthalate, by Bacillus subtilis No. 66. Appl. Microbiol. Biotechnol. 66(6):702-10

Talavera, G., and Castresana, J. 2007. Improvement of phylogenies after removing divergent and ambiguously aligned blocks from protein sequence alignments. 38e44.

Ting, Yang, Lei, Ren , Yang, Jia , Shuanghu, Fan , Junhuan, Wang, Jiayi Wang, Ruth, Nahurira , Haisheng, Wang and 
Yanchun, Yan. 2018. Biodegradation of Di-(2-ethylhexyl) Phthalate by Rhodococcus ruber YC-YTI in Contaminated Water and Soil, Int. Journal of Environ. Res. PublicHealth. 1(5): 15-35.

Toft, G., BO, A., G., Jonsson, and J., P., B. 2012. Association between pregnancy loss and urinary phthalate levels around the time of conception, Environ. Health Perspec. 120(3): 458-463.

Wang and Yanchun, Yan. 2018. Biodegradation of Di-(2-ethylhexyl) Phthalate by Rhodococcus ruber YCYTl in Contaminated Water and Soil. Int. Journal of Environ. Res. Public Health. 15(5): 15-35.

Wang, Y., Fan, Y., and Gu, J., D. 2003. Aerobic degradation of phthalic acid by Comamonas acidovoran Fy-1 and dimethyl phthalate ester by two reconstituted consortia. Biotechnol, 74: 676e672.

Xu, X., R, Li, H., B., and Gu, J., D. 2005 a. Biodegradation of an endocrine- disrupting chemical di-n-butyl phthalate ester by Pseudomonas fluorescens B-1. Int. Biodeterior. and Biodegr. 55: 9e15.

Zhang, L., Liu, J., Liu, H., Wang, and Zhang, S. 2015. The occurrence and ecological risk assessment of phthalate esters (PAEs) in urban aquatic environments of China, Ecotoxicol. 24 (5):967-984.

Zhang, Y., Wang, P., Wang, L., Sun, G., Zhao, J., Zhang, H., and Du, N., 2015. The influence of facility agriculture production on phthalate esters distribution in black soils of northeast China, Sci. Total Environ. 506: 118125.

Zhao, H., Du, H., Lin, J., Chen, X., Li, Y., Li, H., Cai, Q, Mo C, Qin H and Wong M. 2016. Complete degradation of the endocrine disruptor di-(2-ethylhexyl) phthalate by a novel Agromyces sp. MT-O strain and its application to bioremediation of contaminated soil, Sci. Tot. Environ. 562:170e178

\section{How to cite this article:}

Madhavi Rashmi, Sonal Suman and Tanuja. 2020. Screening of Di-2-Ethyl Hexyl Phthalate (DEHP) Degrading Bacteria and its Characterization by Liquid Chromatography Mass Spectrometry Analysis. Int.J.Curr.Microbiol.App.Sci. 9(05): 1499-1507.

doi: https://doi.org/10.20546/ijcmas.2020.905.170 